\title{
The effects of water velocity and morphology on the photosynthetic rate of the aquatic macrophytes Vallisneria americana and $V$. spiralis
}

\author{
Frances E. C. Stewart and Josef D. Ackerman
}

This manuscript reflects the equal contributions of two authors. The project was completed for IBIO 4522 Research in Integrative Biology, Department of Integrative Biology and Faculty of Environmental Sciences,

College of Biological Sciences.

\begin{abstract}
Invasive macrophyte species are generally associated with negative ecological impacts. However, the physiological and morphological characteristics that successfully allow macrophytes to establish in new ecosystems have yet to be determined. In organisms, such as terrestrial angiosperms, algae, and corals morphology, surface area to volume ratio, and water velocity are determining factors in influencing the rate of an individual's physiological processes. Two aquatic macrophytes, Vallisneria americana and Vallisneria spiralis, were used to determine whether leaf morphology influences the photosynthetic rate of aquatic macrophytes in both high $\left(0.026 \mathrm{~m} \mathrm{~s}^{-1}\right)$ and low $\left(0.001 \mathrm{~m} \mathrm{~s}^{-1}\right)$ freestream water velocities. Neither $\mathrm{O}_{2}$ flux $\left(\mu \mathrm{mol} \mathrm{m} \mathrm{m}^{-2} \mathrm{~s}^{-1}\right)$ nor $\mathrm{O}_{2}$ production $(\mu \mathrm{mol})$ significantly differed between species or freestream velocities. However, $\mathrm{O}_{2}$ flux was observed to be highest for $V$. americana at low water velocity. In contrast, $\mathrm{O}_{2}$ flux was highest for $V$. spiralis at high water velocity. This distinction in observed $\mathrm{O}_{2}$ flux implies the morphological difference between $V$. americana and $V$. spiralis affects photosynthetic rate. Further research must be completed to determine physiological causes in this observed difference.
\end{abstract}

$\mathrm{P}$ hysiological ecology describes the physiological mechanisms that explain ecological observations. ${ }^{13}$ Both the physical environment and the morphology of an organism can affect its ecological and physiological performance. ${ }^{26}$ For instance, the physiology of aquatic macrophytes is influenced by environmental factors such as water temperature, water velocity, light intensity, and the morphology of the organism. ${ }^{18,19}$ As with all physiological traits, the surface area/volume ratio (SA/V) has a defining role in the quantity of an aquatic macrophyte's $\mathrm{O}_{2}$ flux, that is, individuals with a larger surface area will produce more $\mathrm{O}_{2}$ than smaller individuals. The larger the plant, the greater the surface area, thus the better it can decrease water velocity across the surface of its leaves, affecting all other physiologic and metabolic processes. ${ }^{26}$

Water velocity affects the ability of many aquatic plants to uptake dissolved inorganic carbon (DIC) influencing the ability to photosynthesise. ${ }^{10}$ For an aquatic macrophyte, optimizing DIC uptake enables the plant to maximize photosynthesis and allocate resources to both growth and reproduction, however, the uptake kinetics of DIC can differ among species, either linearly or non-linearly. ${ }^{20}$ Water motion across the surface of a leaf may be reconfigured from turbulent to laminar flow by the morphology of the organism, directly affecting metabolism and DIC uptake. ${ }^{9}$
An intricate morphology of an aquatic macrophyte can reduce the velocity of the surrounding water; thus increasing DIC uptake and photosynthetic rate. ${ }^{19}$ It is therefore optimal for an aquatic macrophyte to be situated in slow-flowing water, or to be able to reduce the velocity of the water for increased DIC uptake. However, the location of DIC and nutrient uptake can vary with species based on their morphology. ${ }^{7,8,18}$ For example, in Elodia canadensis, $\mathrm{CO}_{2}$ uptake was observed primarily at the mid-rib section of the plant, whereas in Potamogeton crispus, $\mathrm{CO}_{2}$ uptake was uniform throughout each leaf. ${ }^{18}$ The resulting morphology of an aquatic macrophyte affects their ability to obtain nutrients, indicating their capability to survive in areas of low nutrients and DIC through influencing nutrient uptake. ${ }^{11}$

An underlying component to an individual's morphology is the SA/V of the organism. Plants that display an intricate morphology such as whorls, undulations, and coarsely branched leaves, display an increase in SA/V and therefore have the opportunity for an increase in DIC uptake. Reduced ability for DIC uptake occurs when individuals are morphologically basic, being only composed of simple ribbon-like leaves or a central stem. ${ }^{6,} 8$ Increasing morphological complexity can indirectly increase an organism's abundance and distribution across habitats through being able to optimize photosynthetic rate, 


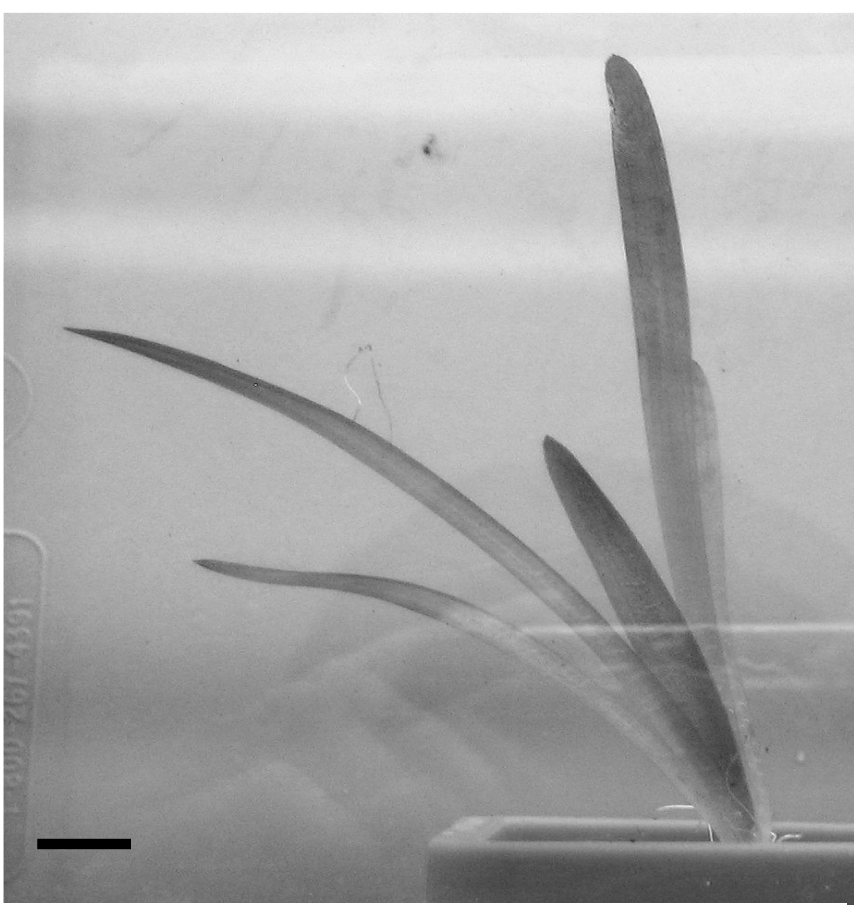

Figure 1A: Vallisneria americana in an aquarium with no flow $\left(0 \mathrm{~m} \mathrm{~s}^{-1}\right)$; scale bar, $1 \mathrm{~cm}$.

enhancing both vegetative and reproductive propagation. ${ }^{26}$

Similar SA/V models have been demonstrated to have functional significance in algae, ${ }^{8,26}$ corals $^{2}$, and terrestrial angiosperms. $^{22,} 25$ Stewart and Carpenter found that the photosynthetic rate of the algae Dictyopteris undulata is influenced by its morphology. ${ }^{26}$ Similar to aquatic macrophytes, algae rely on the movement of water to remove $\mathrm{O}_{2}$ from their surface, and for the delivery of dissolved nutrients. Low flow habitats tend to be occupied by algae species with high $\mathrm{SA} / \mathrm{V}$ to enhance the removal of $\mathrm{O}_{2}$ from the leaf surface, as well as saturate DIC uptake. ${ }^{26,27}$ Similar to macrophytes, nutrient uptake in corals is correlated with water velocity, irradiance, and particularly external nutrient concentration; a general diffusive concept in all aquatic organisms. ${ }^{2}$ Extensive ecophysiological research focusing on the $\mathrm{O}_{2}$ production in terrestrial angiosperms indicates that photosynthesis is dependent upon both leaf and root morphology in nine different boreal tree species independent of relative growth rate. $^{22,25}$ Leaf photosynthesis and respiration rates were correlated to specific leaf surface area in all nine species. ${ }^{22}$ Smith et al. continued to demonstrate that leaf form and photosynthesis are not only affected by $\mathrm{SA} / \mathrm{V},{ }^{25}$ but that leaf structural form evolves in response to the amount of sunlight in terrestrial plants. Extensive ecophysiological research supports the correlation of SA/V with physiological processes.

Most opportunistic and adventive aquatic macrophytes are able to maximize their SA/V and ability to acquire DIC, unlike some native species of macrophyte. The establishment of invasive aquatic macrophytes can drastically alter the ecology of lakes. Generally, exotic invasive macrophytes have higher SA/V and therefore increase epiphyton productivity in the littoral zone. ${ }^{11}$ Understanding the morphological reasons that enable certain macrophytes to maximize nutrient uptake due to increased SA/V will help to predict which species will have the largest impact on food web dynamics, composition, and lake productivity. Viaroli et al. specify that the growth patterns of macrophytes influence the benthic nutrient flux of shallow eutrophic lakes, ${ }^{27}$ affecting ecosystem function. Understanding the relationships between photosynthesis, morphology, and water velocity in aquatic macrophytes is crucial to predicting ecosystem functioning of lakes, potential invasive species, and speciation events.

Currently, climate change is altering lake temperatures, productivity, and species composition. ${ }^{21}$ With these alterations, the stability of the water column increases, decreasing primary productivity. ${ }^{21}$ Such drastic physical changes affect the survival of many species and can result in speciation events, including extinctions. In these situations macrophytes with high DIC affinity could displace species with a lower affinity and sensitivity to DIC increases (V. americana), potentially rendering these species extinct. ${ }^{20}$

To inspect the relationships between photosynthesis, morphology, and water velocity we quantified the photosynthetic rate of two aquatic macrophyte species at two separate freestream velocities. Two freshwater macrophytes

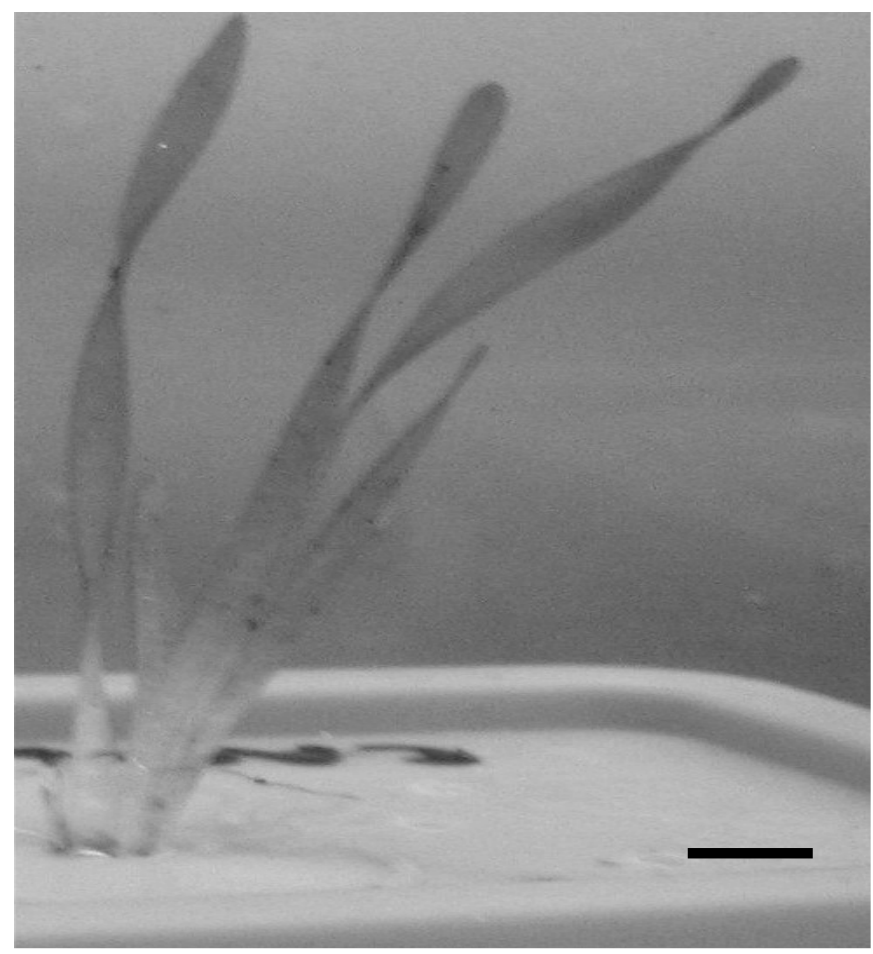

Figure 1B: Vallisneria spiralis in an aquarium with no flow $\left(0 \mathrm{~m} \mathrm{~s}^{-1}\right)$; scale bar, $1 \mathrm{~cm}$. 


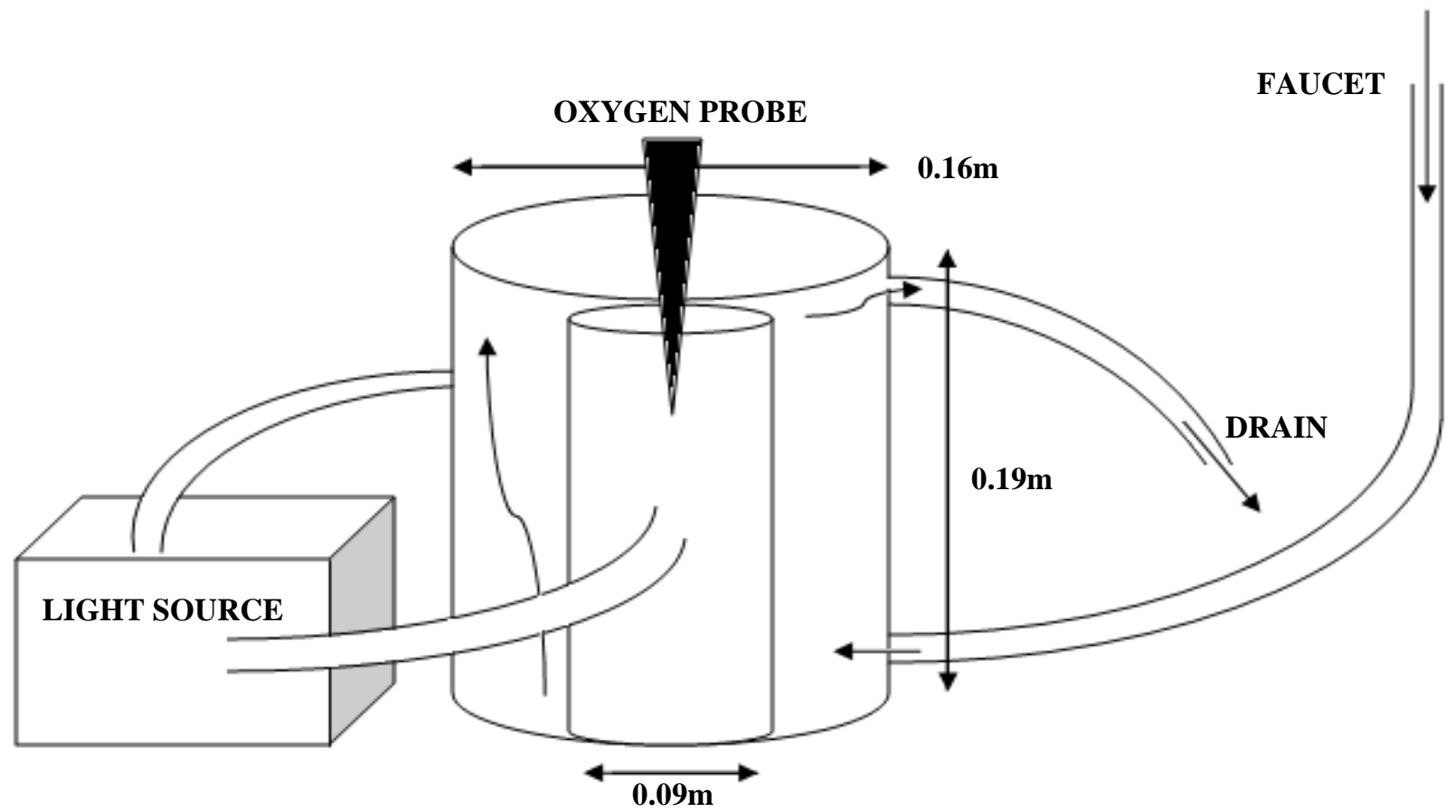

Figure 2: Diagram representing the $700 \mathrm{~mL}$ cylindrical flow chamber, surrounded by a $4 \mathrm{~L}$ water bath used to determine $\mathrm{O}_{2}$ profiles of $V$. americana and $V$. spiralis at both high $\left(0.026 \mathrm{~m} \mathrm{~s}^{-1}\right)$ and low $\left(0.001 \mathrm{~m} \mathrm{~s}^{-1}\right)$ freestream velocities. Filled arrows represent the direction of flow in the surrounding water bath from faucet to drain

that occur throughout Europe and North America are Vallisneria spiralis and Vallisneria americana both of which occupy similar niches in their respective environment. ${ }^{20,24}$ Both plants have a rosette configuration with long ribbonlike leaves; however, the key morphological distinction between the two species is the spiral twist of $V$. spiralis' leaves in comparison to the flat leaves of $V$. americana (Figure 1). In this case we define $V$. spiralis as having an intricate morphology due to the twist in its leaves compared to $V$. americana's simple morphology. Based on this principle we predict that $V$. spiralis will have an enhanced rate of photosynthesis in comparison to $V$. americana, and that photosynthetic rate in both species will increase as water velocity increases. Photosynthesis was measured as the $\mathrm{O}_{2}$ flux at two freestream water velocities and plants were subjected to the same water temperature and light irradiance levels. The objective of this study is to determine if the morphology of an aquatic macrophyte has an effect on photosynthesis when subjected to varying freestream flow velocities.

\section{METHODS}

\section{Aquatic Macrophytes}

Twenty-four $V$. americana Michx. and V. spiralis L. plants (obtained from Boreal Laboratories) were grown on soil substrate in two separate $20 \mathrm{~L}$ aquaria with a 50:50 ratio of
(PAR) was maintained at $140 \mu$ mol photon $\mathrm{m}^{-2} \mathrm{~s}^{-1}$ measured at the centre of the aquaria using a $4 \pi$ sensor (QSL2101, Biospherical Instruments, San Diego, CA, USA), and set to a diel cycle of 12:12h L:D. V. americana and V. spiralis plants that were uprooted were (1) free of epiphytes, (2) without undulations along the leaves in the case of $V$. americana and (3) with a minimum of two spirals per leaf in the case of $V$. spiralis. Preceding each experiment plants were left to acclimate in water at $22^{\circ} \mathrm{C}$ over night. Plants were transported in a sealed Thermos container when travelling between the Hagen Aqualab (University of Guelph) and the Ackerman Physical Ecology lab (University of Guelph) to account for possible temperature shock.

Following each trial, pictures were taken of the uprooted plants and measured to scale. The entire surface area of each plant was determined using ImageJ software and was then incorporated to standardize the calculated $\mathrm{O}_{2}$ flux of each plant. This procedure also takes into account the likelihood that tissue age may influence $\mathrm{O}_{2}$ profiles. The physiologies of these two species were assumed to be similar due to their close phylogenetic relatedness.

\section{Experimental setup}

A specially constructed $700 \mathrm{~mL}$ flow chamber, with a $0.09 \mathrm{~m} \times 0.16 \mathrm{~m}$ centre column surrounded by a $4 \mathrm{~L}$ cylindrical water bath of $0.19 \mathrm{~m} \times 0.16 \mathrm{~m}$ was operated using a magnetic stir bar and stir plate (Figure 2). The centre 
column of water was continuously mixed at one of two velocities; high velocity $\left(0.026 \mathrm{~m} \mathrm{~s}^{-1}\right)$ and low velocity $\left(0.001 \mathrm{~m} \mathrm{~s}^{-1}\right)$. Water was supplied to the water bath from a faucet at a flow rate of $2 \mathrm{~mL} \mathrm{~s}^{-1}$ and the temperature of the centre water column was maintained at $22.9+/-0.2^{\circ} \mathrm{C}$ (mean $+/$ - s.d.). Preceding the experiment by no less than 12 hours, the centre column of the flow chamber was filled with 700 $\mathrm{mL}$ of tap water and left to equilibrate, therefore allowing the vaporization of any gases within the water and permitting the water to reach room temperature $\left(22.4^{\circ} \mathrm{C}\right)$.

Oxygen readings and water temperature were logged every 30 minutes using a YSI-85 hand held dissolved oxygen probe (Model 85-10FT, YSI Inc.). A minimum of 30 minutes elapsed prior to recording the oxygen profiles for each plant, to allow oxygen readings and temperature to equilibrate prior to data collection. Light was provided to the flow chamber by a fibre-optic illuminator (Model NI-150, Dolan-Jenner Industries), which supplied white light without increasing water temperature. PAR readings were maintained at 140 $\mu$ mol photon $\mathrm{m}^{-2} \mathrm{~s}^{-1}$ throughout experimentation.

The freestream velocity profiles of the filled flow chamber were determined using a 3-beam SonTech acoustic Doppler velocimeter (ADV), with a sampling volume situated $0.05 \mathrm{~m}$ below the sensor head. ${ }^{14}$ Measurements at the location of the plant, approximately $0.05 \mathrm{~m}$ from the water surface and $0.007 \mathrm{~m}$ from the centre of the water column, were taken for both high (300 rpm) and low (60 rpm) stir bar settings. Due to the circular water motion in the water column, water velocity was measured by calculating kinetic energy, rather than linear velocity. The kinetic energy of the water was calculated using the equation:

$$
\mathrm{E}_{\mathrm{k}}=1 / 2\left(v^{2}+u^{2}+w^{2}\right)
$$

where $v$ is the velocity in the axial plane $\left(\mathrm{m} \mathrm{s}^{-1}\right), u$ is the velocity in the vertical plane $\left(\mathrm{m} \mathrm{s}^{-1}\right)$, and $w$ is the velocity in the transverse plane $\left(\mathrm{m} \mathrm{s}^{-1}\right)$. Water velocity measurements were described using the kinetic energy value, high velocity equalling $0.026 \mathrm{~m} \mathrm{~s}^{-1}$, and low velocity equalling $0.001 \mathrm{~m} \mathrm{~s}^{-1}$. To minimize the effects of growth rate on oxygen production, a randomized block design was used to select plants and to determine the sequence of trials. A total of five $V$. americana, and five $V$. sprialis plants were used at both high and low water velocities giving a sample size of $\mathrm{N}=5$ for all four treatments.

\section{Statistical analysis}

S-PLUS 8.0.4 statistical software (Enterprise Developer, 2007) was used to compare the $\mathrm{O}_{2}$ flux at high $\left(0.026 \mathrm{~m} \mathrm{~s}^{-2}\right)$ and low $\left(0.001 \mathrm{~m} \mathrm{~s}^{-2}\right)$ water velocities for both $V$. americana and $V$. spiralis. Non-parametric data with unequal variances required the use of a Friedman's two-way ANOVA. Twoway Wilcox-Mann-Whitney t-tests were subsequently used to compare treatments. Both Friedman's and Wilcox-MannWhitney tests were repeated to compare $\mathrm{O}_{2}$ produced as a comparison to $\mathrm{O}_{2}$ flux values. Obtained $\mathrm{P}$-values were considered to be significantly different if less than 0.05 . Values are reported as mean +/- 1 s.e.m. unless otherwise noted.

\section{RESULTS}

\section{$\mathrm{O}_{2}$ flux}

The $\mathrm{O}_{2}$ flux at high and low water velocities for $V$. americana and $V$. spiralis were not significantly different $(\mathrm{df}=1, \mathrm{P}=0.7147)$ (Figure 3). Oxygen flux values were on the order of 10 magnitudes less than previously determined for $V$. americana and $V$. spiralis at similar water velocities, ${ }^{20}$ and are comparable to other studies concerning aquatic macrophytes. ${ }^{17,19}$

Disregarding the two different species, no significant difference in $\mathrm{O}_{2}$ flux was observed between high and low water velocities $(\mathrm{P}=0.9118)$. When disregarding water velocity, no significant difference was observed between the two species $(\mathrm{P}=0.4359)$ (Figure 2).

When comparing $\mathrm{O}_{2}$ flux at only high velocity between $V$. americana and $V$. spiralis, no significant difference was observed $(\mathrm{P}=0.4206)$. Similarly no significant difference was observed when comparing $\mathrm{O}_{2}$ flux at low velocity $(\mathrm{P}=0.8413)$. However, overall, $\mathrm{O}_{2}$ flux was highest for $V$. americana at high velocities, where as contrastingly, $\mathrm{O}_{2}$ flux was highest for $V$. spiralis at low velocities (Table 1).

Table 1: Mean $\mathrm{O}_{2}$ flux at both high $\left(0.026 \mathrm{~m} \mathrm{~s}^{-1}\right)$ and low $\left(0.001 \mathrm{~m} \mathrm{~s}^{-1}\right)$ water velocities for both Vallisneria americana and Vallisneria spiralis. $N=5$, values are means +/- 1 s.e.m.

\begin{tabular}{|llll|}
\hline Species & $\mathbf{N}$ & Velocity $\left(\mathrm{m} \mathrm{s}^{-1}\right)$ & Mean $\mathbf{O}_{2}$ flux $\left(\mu \mathrm{mol} \mathrm{m}^{-2} \mathrm{~s}^{-1}\right)$ \\
\hline V. americana & 5 & High $(0.026)$ & $0.0139+/-1.54 \times 10^{-3}$ \\
\hline ericana & 5 & Low $(0.001)$ & $0.0209+/-8.16 \times 10^{-3}$ \\
\hline V. spiralis & 5 & High $(0.026)$ & $0.0229+/-6.15 \times 10^{-3}$ \\
\hline V. spiralis & 5 & Low $(0.001)$ & $0.0160+/-2.83 \times 10^{-3}$ \\
\hline
\end{tabular}




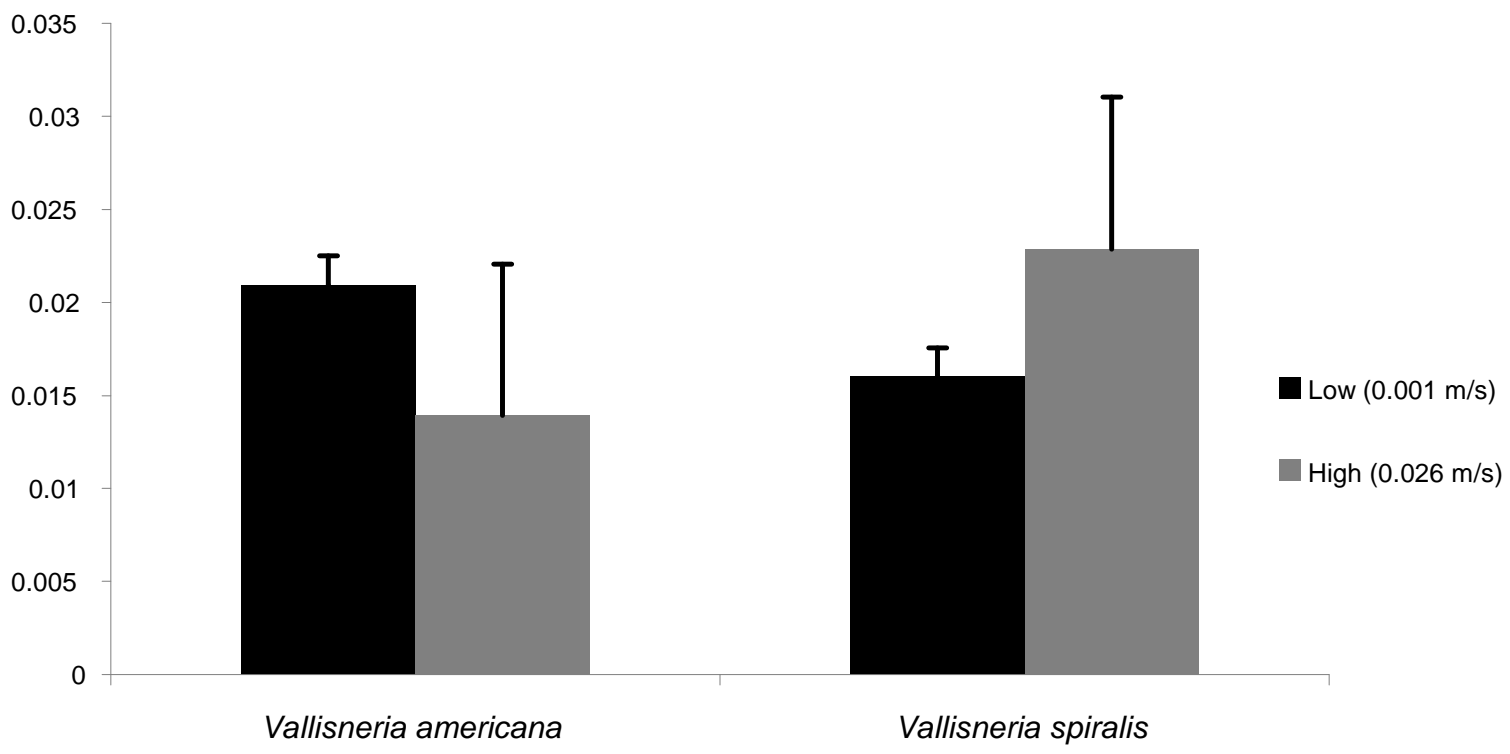

Species

Figure 3: $\mathrm{O}_{2}$ flux determined from Vallisneria americana and Vallisneria spiralis at both high $\left(0.026 \mathrm{~m} \mathrm{~s}^{-1}\right)$ and low $\left(0.001 \mathrm{~m} \mathrm{~s} \mathrm{~s}^{-1}\right)$ freestream water velocities. Values are means $+/-1$ s.e.m. In all treatments $N=5$. $\mathbf{O}_{2}$ flux values were determined to be nonsignificantly different between treatments $(P=0.7147)$.

\section{$\mathrm{O}_{2}$ produced}

Friedman's two-way ANOVA and two-way Wilcox-MannWhitney t-tests were repeated by comparing $\mathrm{O}_{2}$ produced $(\mu \mathrm{mol})$ rather than $\mathrm{O}_{2}$ flux $\left(\mu \mathrm{mol} \mathrm{m} \mathrm{s}^{-2} \mathrm{~s}^{-1}\right)$. Similar treatment groups were not significantly different; however, P-values decreased in each comparison to the $\mathrm{O}_{2}$ flux statistical tests, indicating possible biological significance rather than statistical significance. No statistical significant difference was found between all four treatments in oxygen production at both the high or low velocities $(\mathrm{df}=1, \mathrm{P}=0.5166)$ (Figure 4). Oxygen production did not significantly differ between high and low velocities $(\mathrm{P}=0.2670)$ or between $V$. americana and $V$. spiralis $(\mathrm{P}=0.1258)$. Furthermore, no difference was observed in $\mathrm{O}_{2}$ produced between $V$. americana and $V$. spiralis at high velocities $(\mathrm{P}=0.1412)$ or at low velocities $(\mathrm{P}=0.7449)$. However, $\mathrm{O}_{2}$ production was greater at high velocities than low velocities for both species (Figure 4).

\section{DisCUSSION}

\section{$\mathrm{O}_{2}$ flux}

Measuring $\mathrm{O}_{2}$ flux allows for the standardization of the amount of oxygen flowing per unit surface area per unit time. This calculation is critical and accounts for both plant size and duration of photosynthesis; two factors with high variability during measurement of produced $\mathrm{O}_{2}$. Although all $\mathrm{O}_{2}$ flux comparisons were not statistically significant, visual comparisons of the data indicate that dissimilarity in $\mathrm{O}_{2}$ production exists between the two species. This may be due to the simple spiral difference in their morphology. In these comparisons, the data was biologically significant rather than statistically significant. Unlike other research comparing water velocity, morphology, and $\mathrm{O}_{2}$ flux of aquatic macrophytes, ${ }^{17,} 20$ the null hypothesis is accepted in this research, indicating no-significant statistical difference between water velocity, $\mathrm{O}_{2}$ flux, and morphology in $V$. americana and $V$. spiralis.

Interestingly, contrasting trends were observed between species. Oxygen flux at high water velocity in $V$. americana was similar to $\mathrm{O}_{2}$ flux in $V$. spiralis at low water velocity. Similarly, $\mathrm{O}_{2}$ flux in $V$. americana at low water velocity was similar to $\mathrm{O}_{2}$ flux in $V$. spiralis at high water velocity (Figure 3) (Table 1). Although statistically non-significant, inspection of the data demonstrated the ability of an intricate morphology to decrease the water velocity across the leaf surface, which may enhance the ability for optimal DIC uptake. ${ }^{9}$ This data implies that in the case of $V$. spiralis at high water velocities, the spiral twist of its leaves reduced the water velocity, increasing photosynthetic rate. At low water velocities, slow water movement may have prevented the removal of $\mathrm{O}_{2}$ from the leaf surface. ${ }^{26}$ Conversely, the opposite scenario applies to $V$. americana. The simple ribbon-like leaves of $V$. americana may allow for ample removal of $\mathrm{O}_{2}$ from the leaf surface at low water velocities, however, as water velocity increases, the leaf is unable to reduce water velocity across its surface to a velocity suitable for photosynthesis. ${ }^{20,26}$ 


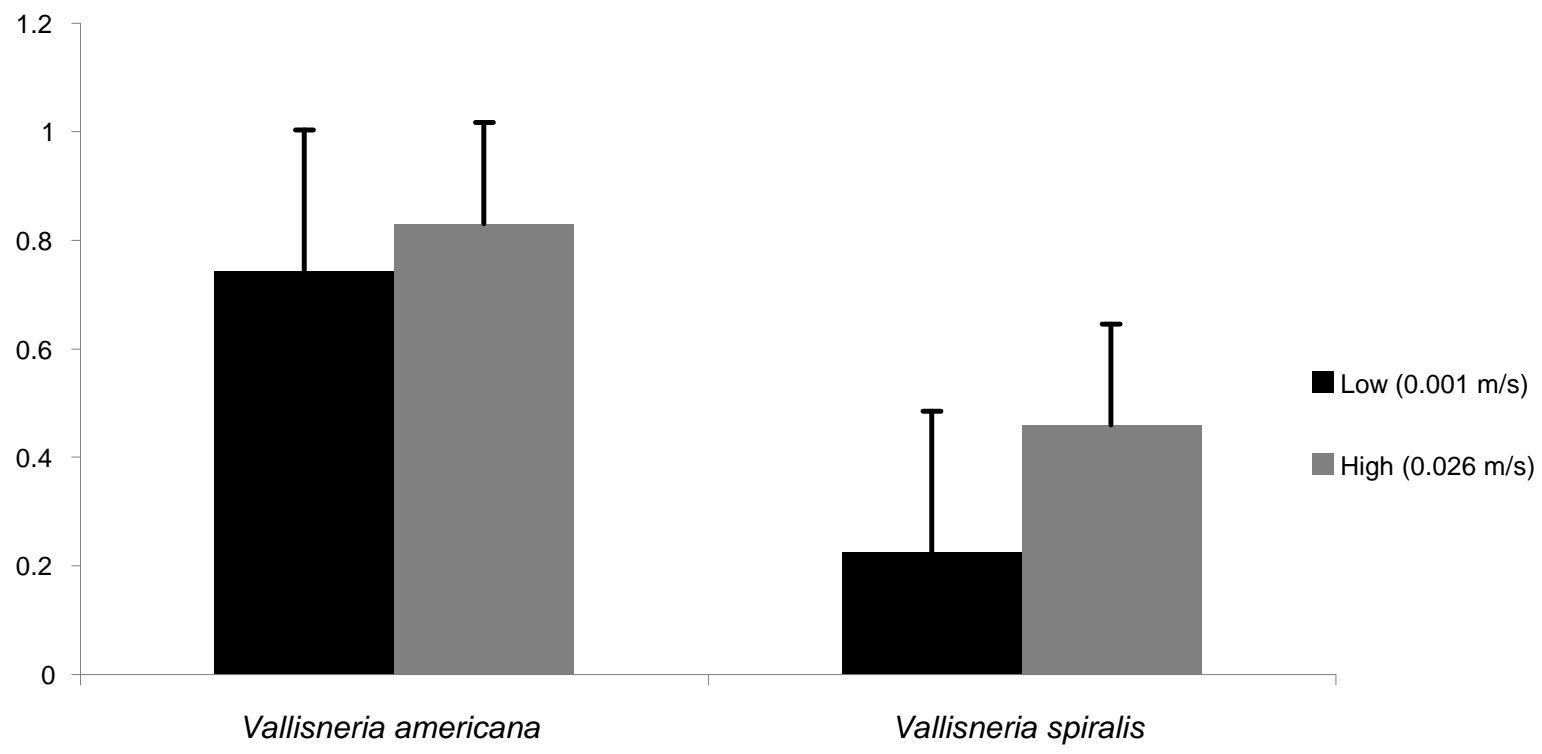

Species

Figure 4: $\mathrm{O}_{2}$ production values determined from Vallisneria americana and Vallisneria spiralis at both high and low freestream water velocities. Values are means +/- 1 s.e.m. In all treatments $\mathrm{N}=5 . \mathrm{O}_{2}$ flux values were determined to be non-significantly different between treatments $(P=\mathbf{0 . 5 1 6 6})$.

\section{$\mathrm{O}_{2}$ produced}

Comparing $\mathrm{O}_{2}$ produced $(\mu \mathrm{mol})$ rather than $\mathrm{O}_{2}$ flux $\left(\mu \mathrm{mol} \mathrm{m}^{-2} \mathrm{~s}^{-1}\right)$ revealed statistically non-significant differences between $V$. americana and $V$. spiralis at both high and low freestream water velocities. However, in all comparisons, $\mathrm{P}$-values were smaller than during $\mathrm{O}_{2}$ flux analyses. Additionally, for both species, maximal $\mathrm{O}_{2}$ production was observed at high velocities (Figure 4), compared to maximal $\mathrm{O}_{2}$ flux observed at low water velocity in the case of $V$. americana (Figure 3). These contrasting results highlight the importance of standardizing data by leaf tissue amount. In the case of $V$. americana plants at low water velocities produce contrastingly more $\mathrm{O}_{2}$ per SA/V compared to either $V$. americana plants at high velocities or V.sprialis plants at either high or low water velocities. Therefore, SA/V ratio has a greater effect on $\mathrm{O}_{2}$ flux in $V$. americana than in $V$. spiralis.

\section{Future research}

Non-statistically significant results may be attributed to small data values with extreme variance obtained from this study. Future studies should aim to increase the sample size to a minimum of $\mathrm{N}=10$ for all treatments. This increase could potentially lead to divergence in $\mathrm{O}_{2}$ flux between $V$. americana and $V$. spiralis as well as decreasing variation in obtained measurements. Maximal water velocity in the flow chamber utilized was $0.026 \mathrm{~m} \mathrm{~s}^{-1}$, however, utilization of other flume techniques would allow for an increase in water velocity. As well, multiple treatments of continually increasing water velocities could contain the potential to highlight any discrepancies in water velocity comparisons.

A common fault in measuring colonial organisms consists of pseudoreplication through measuring ramets rather than the genet; that is, measuring functionally rather than genetically distinguishable organisms. Assuming the original $24 \mathrm{~V}$. americana and $V$. spiralis plants obtained from Boreal Laboratories were genetically distinct, the above sampling design is not pseudoreplicated. However, the utilized macrophytes have undergone vegetative propagation in both $20 \mathrm{~L}$ aquaria, with random individuals being selected for sampling. Due to this random sampling design there was no guarantee that two individuals sampled were genetically distinct and may in fact belong to the same genet, resulting in potential non-independence of replicates. Genetic analysis of individuals would clarify whether functionally or genetically distinguishable individuals were being sampled. However, vegetative propagation occurs frequently within ecological populations. Therefore, sampling several ramets may in fact be more representative of ecological circumstances, compared to samples being genetically distinct.

It is also possible that the correlation between increasing $\mathrm{SA} / \mathrm{V}$ with $\mathrm{O}_{2}$ is a consequence of phylogenetic characteristics rather than morphological characteristics of these species. Genetic or evolutionary history discrepancies between species may explain differences in observed $\mathrm{O}_{2}$ flux. However, a single phylogenetic divergence event has occurred between $V$. americana and $V$. spiralis, rendering them each other's closest phylogenetic relative and were 

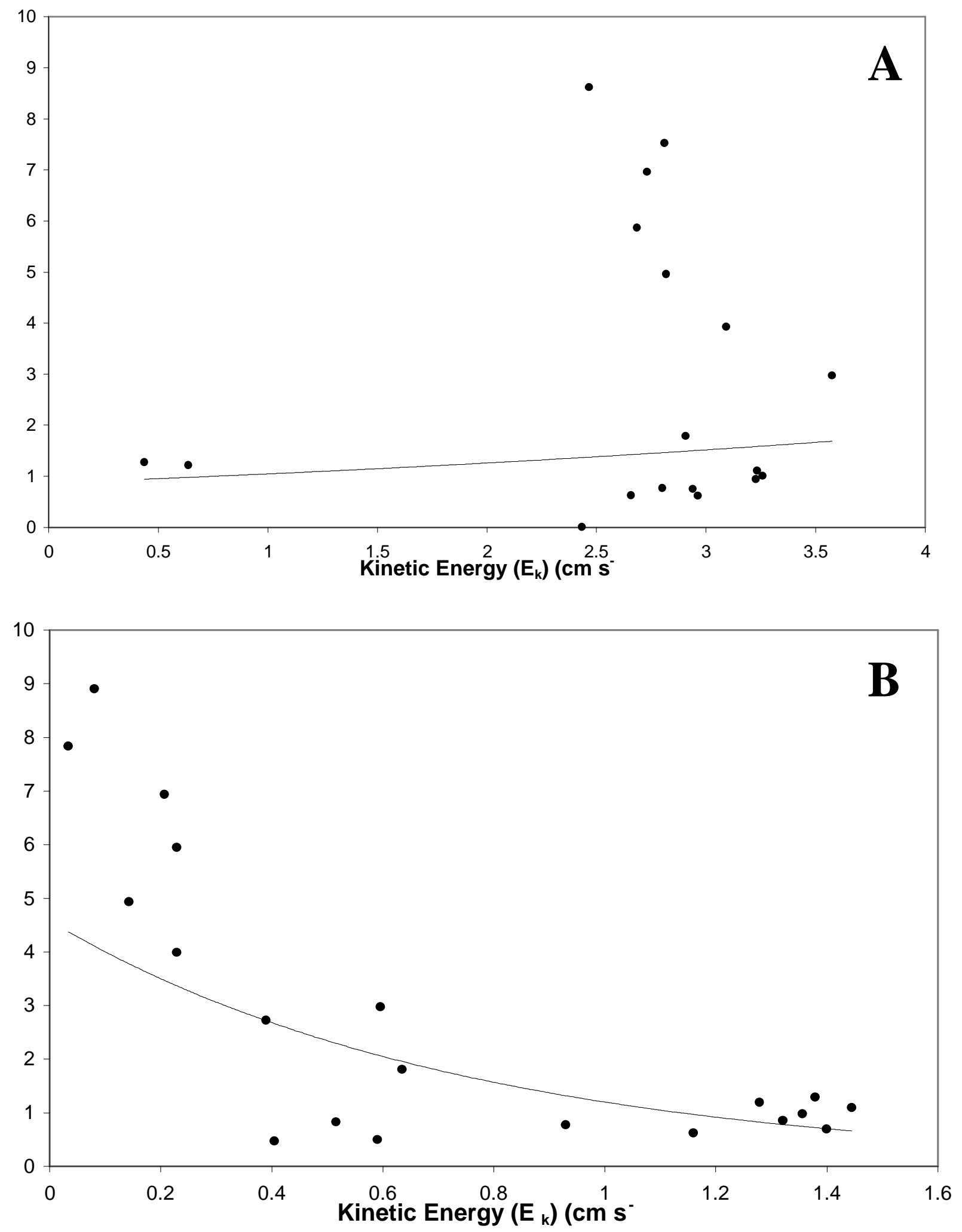

Figure 5: Velocity profiles of the cylindrical $700 \mathrm{~mL}$ flow chamber at a stir bar rotation velocity of (A) $300 \mathrm{rpm}$ and (B) $60 \mathrm{rpm}$. All measurements were made $0.007 \mathrm{~m}$ from the centre of the cylindrical column of water. The dashed line represents the average height at which each plant was located in the flow chamber, indicating the average height at which kinetic energy was calculated. 
therefore assumed to have similar metabolic rates. ${ }^{6}$ Stewart and Carpenter also conclude that physiological studies involving SA/V transcend phylogenetic boundaries, ${ }^{26}$ rendering any phylogenetic divergence between species an improbable cause of any difference in $\mathrm{O}_{2}$ flux. It is unlikely that any observed difference in $\mathrm{O}_{2}$ flux between $V$. americana and $V$. spiralis is due to phylogenetic dissimilarities.

Changes in $\mathrm{O}_{2}$ flux may have been undetected due to limitations in oxygen sensor accuracy (YSI 85-10FT accuracy of $+/-2 \%$ ), resulting in no statistical difference in $\mathrm{O}_{2}$ detected between species or water velocities. Utilization of an oxygen sensor with increased sensitivity would eliminate the doubt of minor quantities of $\mathrm{O}_{2}$ being unnoticeably produced. Nishihara and Ackerman indicate that the concentration boundary layer surrounding a plant is negatively affected by microsensors. ${ }^{20}$ A similar concept may be applied to the $\mathrm{O}_{2}$ sensor used in this technique. Continual movement of the YSI oxygen probe was required to obtain an accurate $\mathrm{O}_{2}$ reading; however, this movement would undoubtedly disrupt the concentration boundary layer and introduce atmospheric oxygen into the water sample. This process potentially disrupts the $\mathrm{O}_{2}$ flux recorded from the macrophyte. The technique used in this study has potential for improvements, and must be refined to entirely eliminate any possible external oxygen sources from affecting $\mathrm{O}_{2}$ flux readings. Designing a flow chamber customized for the specified oxygen probe and increasing water velocity would eliminate the necessity for manual mixing of the YSI $\mathrm{O}_{2}$ probe.

Water velocity profiles of the $700 \mathrm{~mL}$ flow chamber were not analyzed until after experimentation, and were revealed to be non-uniform in shape at the height of the plant (Figure 5A, B). High variability in velocity depended upon the boundary distance at which velocity was measured, resulting in an inconsistent velocity profile. Profiles contrasted between high velocity (300 rpm) and low velocity $(60 \mathrm{rpm})$ measurements, with a positive linear relationship demonstrated at $300 \mathrm{rpm}$, and a negative exponential relationship at $60 \mathrm{rpm}$. These contrasts in water velocity profiles have the potential to account for discrepancies observed in $\mathrm{O}_{2}$ flux measurements. Future studies must utilize a tested flow chamber with uniform stable water velocity profiles to obtain accountable $\mathrm{O}_{2}$ flux profiles for $V$. americana and $V$. spiralis.

Alterations to the experimental procedure described above could potentially include $\mathrm{CO}_{2}$ kinetic and $\mathrm{pH}$-drift experiments during each trial, testing for a potential difference in the affinity for DIC between species. ${ }^{17,}{ }^{23}$ No difference in DIC affinity would support the above nonsignificant results. Individual leaves of $V$. spiralis have previously been demonstrated to have increased DIC affinity over $V$. americana, however, this result has not yet been supported in an intact plant in freestream velocities. ${ }^{17,20}$

\section{Ecological implications}

Discerning the proportions to which morphologic and abiotic variables influence physiological processes is complex. Understanding how environmental, phylogenetic, and morphological factors influence macrophyte survival will help to predict possible speciation and extinction events that are imminent during current and future climate change events. The acidification of marine ecosystems due to increases in atmospheric $\mathrm{CO}_{2}$ provides pertinent motivation to promptly understand these relationships for aquatic ecosystem conservation, aquatic macrophyte distribution, and potential freshwater remediation.

\section{Conclusion}

Previous studies have concluded the importance of SA/V and water velocity on physiological processes in aquatic macrophytes. Quantification of these variables on photosynthetic rate of intact $V$. americana and $V$. spiralis plants in freestream velocity was attempted in this research. Lack of statistical significance in this study prevents concrete conclusions being stated in regards to $\mathrm{O}_{2}$ flux of $V$. americana and $V$. spiralis at high and low freestream water velocities. Although not significant, there was an observable increase in $\mathrm{O}_{2}$ flux of $V$. spiralis at high water velocities, which may be attributed to the spiral twists of the leaves. Future potential research could eliminate the spiral twist of $V$. spiralis in freestream water velocities, as well as measure water $\mathrm{pH}$ changes during photosynthesis to determine if increased $\mathrm{O}_{2}$ flux at high water velocities is due to increased metabolic activity or leaf morphology. Further research is essential to discern the effects of morphology and velocity on the ecophysiological processes of aquatic macrophytes.

\section{Acknowledgments}

The authors would like to thank Steve Wilson, Ian Renaud, and Ian Smith for technical assistance with equipment. This research was supported in part by funding from the University of Guelph and the Natural Sciences and Engineering Research Council of Canada to J.D.A.

\section{REFERENCES}

1. Anderson, M. S., and Charters, A. C. (1982). A fluid dynamics study of seawater flow through Gelidium nudifrons. Limnology and Oceanography. 27(3), 399412.

2. Badgley, B.D., Lipschultz, F. and Sebens, K.P. (2006). Nitrate uptake by the reef coral Diploria stribosa: effects of concentration, water flow, and irradiance. Mar. Biol. 149, 327-338.

3. Conlin, K.C., and Sears, P.L. (1996) Control of Algae in PlantedAquaria.http://www.thekrib.com/Plants /Fertilizer/sears-conlin.html accessed February 5, 2009. 
4. Corneilsen, C. D., Thomas, F. M. (2006). Water flow enhances ammonium and nitrate uptake in seagrass community. Mar. Ecol. Prog. Ser. 312, 1-13.

5. Gonen, Y., Kimmel, E., and Friedlander, M. (1995). Diffusion boundary layer transport in Gracilaria conferta (Rhodophyta). Journal of Phycology. 31, 768 773.

6. Hasalm, S. M. (1934). River plants. Cambridge University Press.

7. Helmuth, B. S. T., Sebens, K. P. and Daniel, T. L. (1997). Morphological variation in coral aggregations: branch spacing and mass flux to coral tissues. J. Exp. Mar. Biol. Ecol. 209, 233 - 259.

8. Hurd, C. L., Harrison, P. J. and Druehl, L. D. (1996). Effect of seawater velocity on inorganic nitrogen uptake by morphologically distinct forms of Macrocystis integrifolia from wave-sheltered and exposed sites. Mar. Biol. 126, 205-214.

9. Hurd, C. L., and Stevens, C. L. (1997). Flow visualisation around single- and multiple-bladed seaweeds with various morphologies. Journal of Phycology. 33, 360 - 367.

10. Hurd, C.L. (2000). Water motion, marine macroalgal physiology, and production. Journal of Phycology. 36, $456-461$.

11. Kelly, D.J., and Hawes, I. (2005). Effects of invasive macrophytes on littoral-zone productivity and foodweb dynamics in a New Zealand high-country lake. J. N. Am. Benthol. Soc. 24(2),300-320.

12. Kirk, J.T.O. (1935). Light and photosynthesis in aquatic ecosystems. Cambridge University Press.

13. Lambers, H., Chapin, F. S., Pons, T. L. (1998). Plant Physiological Ecology. Springer.

14. Lassen, J., Kortegård, M., Riisgård, H.U., Friedrich, M., Gerhard, G., and Larsen, P.S. (2006). Down-mixing of phytoplankton above filter feeding mussels-interplay between water flow and biomixing. Mar Ecol Prog Ser 314, 77-88.

15. Les, D.H., Cleland, M.A., and Waycott, M. (1997). Phylogenetic Studies in Alismatidae, II: Evolution of Marine Angiosperms (Seagrasses) and Hydrophily. Systematic Botany. 22(3), 443-463.

16. Lcozy, S., Carignan, R., Planas, D. (1983). The role of roots in carbon uptake of the submersed macrophytes Myriophylum spicatum, Vallisneria americana, and Heteranthera dubia. Hydrobiologia 98, 3 -7.

17. Madsen, T. M., and Sand-Jensen, K. (1991). Photosynthetic carbon assimilation in aquatic macrophytes. Aquat. Bot. 41, 5-40.

18. Neilson, H. D., Neilson, S. L, and Madsen, T. V. (2006). $\mathrm{CO}_{2}$ uptake patterns depend on water current velocity and shoot morphology in submerged macrophytes. Freshwater Biology 51, 1331-1340.
19. Nishihara, G. N., and Ackerman, J. D. (2006). The effect of hydrodynamics on the mass transfer of dissolved inorganic carbon in the freshwater macroophyte Vallisneria Americana. Limnol. Oceanogr. 51(6), 27342745.

20. Nishihara, G. N., and Ackerman, J. D. (2007). The interaction of $\mathrm{CO}_{2}$ concentration and spatial location on $\mathrm{O}_{2}$ flux and mass transport in the freshwater macrophytes Vallisneria spiralis and V.americana. Journal of Experimental Biology. 210, 522-532.

21. O'Riley, C.M., Alin, S.R., Plisnier, P., Cohen, A.S., and McKee, B.A. (2003). Climate changes decrease aquatic ecosystem productivity of lake Tanganyika, Africa. Letters to Nature 424,766 - 768.

22. Reich, P.B., Walters, M.B., Tjoelker, M.G., Vanderklein, D., and Buschena, C. (1998). Photosynthesis and respiration rates depend on leaf and root morphology and nitrogen concentration in nine boreal tree species differing in relative growth rate. Functional Ecology 12, 395-405.

23. Sand-Jensen, K., Pedersen, M.F., and Neilsen, S.L. (1992). Photosynthetic use of inorganic carbon among primaryand secondary water plants in streams. Freshwater Biology 27, 283-293.

24. Sculthorpe, C. D. (1967). The Biology of Aquatic Vascular Plants. London: Edward Arnold.

25. Smith, W.K., Vogelman, T.C., DeLucia, E.H., Bell, T.D., and Shepard, K.A. (1997) Leaf form and photosynthesis. BioScience 47(11), 785-793.

26. Stewart, H.L., and Carpenter, R.C. (2003). The effects of morphology and water flow on photosynthesis of marine macroalgae. Ecology 8(11), 2999-3012.

27. Viaroli, P., Bartoli, B., Bondavalli, C., Christian, R.R., Giordani, G., and Naldi, M. (1996). Macrophyte communities and their effect on bethnic flux of oxygen, sulphide and nutrients in shallow eutrophic environments. Hydrobiologia 325, 109-119.

\section{SUPPLEMENTARY MATERIAL}

\section{Plant care}

Twenty-four $V$. americana and $V$. spiralis plants were obtained from Boreal Laboratories approximately four months prior to experimentation. Plants were permitted to grow on a 12:12 diel cycle, in two separate aquaria with a soil substrate and an aeration stone. Three lights were used to ensure that adequate red and blue wavelengths were present for absorption by chlorophyll a and $\mathrm{b}$; two metal halide bulbs and one compact fluorescent bulb. ${ }^{12}$ All three lights were hung above the two aquaria and PAR was maintained at 140 $\mu$ mol photon $\mathrm{m}^{-2} \mathrm{~s}^{1}$ measured at the centre of the aquaria using a $4 \pi$ sensor (QSL2101, Biospherical Instruments, San Diego, CA, USA). Aquaria were observed daily, and any 
excess algae were removed. Water in the aquaria was initially composed of 50:50 well water: distilled water; however, only distilled water was added to the aquaria when re-filling to prevent water hardness from continually increasing.

After approximately one month, both algae and snails became excessive in both aquaria, and a method to reduce the quantity of algae in both tanks was sought after. After extensive research and consulting with both botanists and pet store aquarium personnel the method of Poor Man's Dupla Drops (PMDD) was applied. ${ }^{3}$ PMDD was mixed and administered in daily doses of 2 drops/ aquaria. Plants received PMDD for approximately one month prior to and throughout experimentation.

\section{Technique Development}

Originally a specially constructed 40 L flow chamber of 1.0 $\mathrm{m} \times 0.15 \mathrm{~m} \times 0.15 \mathrm{~m}$ was used with flow straighteners in the first $0.25 \mathrm{~m}$. Water in the flow chamber was maintained at $20^{\circ} \mathrm{C}$ and flowed at one of six different freestream velocities at the leading edge of the plant: $0.01,0.02,0.05,0.08,0.10$ or $0.15 \mathrm{~m} \mathrm{~s}^{-1}$. These velocities are similar to velocities experienced by $V$. americana and $V$. spiralis in their natural environment. ${ }^{6,12}$ Prior to use, velocity profiles in the flow chamber were determined to be uniform in shape through using particle image velocimetry (PIV). Plants were situated in the middle of the flow chamber at $0.80 \mathrm{~m}$ downstream from the straighteners.

This $40 \mathrm{~L}$ flume apparatus was able to maintain stable water temperature readings of $20.7+/-0.4{ }^{\circ} \mathrm{C}$ as well as percent oxygen values of $89+/-1.2 \%$ with no plant present. However, constant equipment failures such as a leaking motor, three failed brass, copper, and teflon ball bearings within two months, and a failed thermocouple requiring five weeks to repair, proved this flume impractical for this experiment. It was also postulated that the volume of this flume was simply too great to note an observable change in $\mathrm{O}_{2}$ flux from a single plant within 6 hours of operation. After this decision the $4 \mathrm{~L}$ flume was incorporated. A control trial was obtainable in the $4 \mathrm{~L}$ flume in which $\mathrm{O}_{2}$ was maintained at $72.3+/-0.4 \%$ and temperature was maintained at $22.9+/-$ $0.2^{\circ} \mathrm{C}$. The flow chamber was run for approximately 90 minutes prior to the beginning of a trial to permit $\mathrm{O}_{2}$ and temperature to equilibrate. Each plant remained in the flume for a duration of approximately 2 hours, resulting in a total of 3.5 hours required for each trial.

Continual concerns arose regarding the YSI dissolved $\mathrm{O}_{2}$ probe (YSI 85-10 FT). After comparison to multiple other $\mathrm{O}_{2}$ probes, and talking to an YSI technician, it was determined that the YSI probe was no longer properly functioning. After fixing this problem, there was concern that the YSI probe simply would not be sensitive enough to observe a difference in $\mathrm{O}_{2}$ flux over a reasonable amount of time. This problem was solved by means of the smaller $4 \mathrm{~L}$ flume.

Tap water is naturally saturated with dissolved $\mathrm{O}_{2}$ gas, denoting that no $\mathrm{O}_{2}$ produced from photosynthesis will dissolve into the water used for trials. It is imperative that the water used for experimentation is slightly hypoxic. Several methods for purging water of $\mathrm{O}_{2}$ were attempted, however, bubbling with nitrogen gas was the most efficient. Adding sodium sulphite allowed water to remain hypoxic for a four hour time period, however, it prevented an observable change in $\mathrm{O}_{2}$ flux by reacting with any $\mathrm{O}_{2}$ that was produced through photosynthesis.

Prior to implementation of PMDD into the plant care protocol a decrease in $\mathrm{O}_{2}$ of $2 \%$ per hour was observed in the $40 \mathrm{~L}$ flume, indicating that the plant was consuming $\mathrm{O}_{2}$ through respiration. However, supplementing aquaria water with PMDD both corrected for this decrease in $\mathrm{O}_{2}$ during a trial as well as prevented algal growth in the aquaria.

Velocity profiles for the $4 \mathrm{~L}$ cylindrical flume were determined using ADV and kinetic energy calculations allowed for the determination of freestream velocity within the centre column of the flume (Eqn 1). Due to the skewed velocity profiles at both $300 \mathrm{rpm}$ (Figure 5A) and $60 \mathrm{rpm}$ (Figure 5B), kinetic energy calculations were only completed and averaged over the area where the plant was placed during trials; 0.05 to $0.08 \mathrm{~m}$ from the water surface and $0.007 \mathrm{~m}$ from the centre of the water column.

Substantial set backs were encountered in the technique development portion of this experiment, and these set backs are reflected in the small sample size observed. In the future this experiment would preferably continue for a longer period of time so that a larger sample size in the $4 \mathrm{~L}$ flume could be obtained. 